\title{
EL TRIUNFO DE LA MINERÍA INFORMAL. CONFLICTOS POR EL CONTROL DE LOS RECURSOS MINEROS EN CARANGAS A FINES DEL SIGLO XVIII
}

\author{
María Concepción Gavira Márquez
}

\section{^ Introducción}

Resumen

La crisis minera de fines del siglo XVIII en Carangas provocó la disminución de los recursos y la competencia por su control entre un pequeño grupo compuesto por azogueros, rescatistas de mineral (población indígena y mestizos) y la burocracia. Los conflictos y tensiones llegaron hasta la Audiencia de Charcas en varias ocasiones. A través de estos expedientes coloniales analizaremos las pugnas desatadas al producirse un desequilibrio en el estatus de la región con la llegada del nuevo subdelegado, el cual emprendió negocios por su cuenta entrando en competencia con los dos azogueros del partido. En medio de este conflicto se encontraba la población tributaria, la cual supo sacar provecho a la situación de enfrentamiento entre la máxima justicia de la jurisdicción local y los azogueros. Los tributarios de Todos Santos habían comprobado cuán perjudicial era la asociación de los azogueros y las autoridades locales y, con la llegada del subdelegado y su negocio de rescate de plata, consiguieron cierta independencia con el triunfo de la minería informal, llevada a cabo por mujeres, jucos y buscones.

Palabras claves: minería colonial - Carangas - jucos.

Abstract

The mining crisis of the late eighteenth century in Carangas provoked a decline in resources and competition for control among a small group consisting of silver-refiners, ore-collectors (Indigenous and Mestizo) and bureaucrats, whose conflicts and tensions came to the attention of the Audiencia de Charcas on several occasions. Using colonial records we analyze the struggles that evolved as an imbalance that occurred in the status of the region with the arrival of a new Subdelegado, who set up his own business in competition with the two silver-refiners of the Province (Partido). The tributary population of Todos Santos found itself in the midst of this conflict, and was able to take advantage of the confrontational situation between the highest judge of the jurisdiction and the silver-refiners. The tributaries realized the seriousness of the damage that occurred between the silverrefiners and local authorities, but with the arrival of the Subdelegado and his silver-purchasing business they gained some independence by resorting to informal mining, carried out by women, jucos and ore-collectors.

Key words: colonial mining - Carangas - jucos - ore-collectors.

Recibido: julio 2014. Aceptado: octubre 2014.
El corregimiento y posterior partido de Carangas representa una región especialmente interesante como laboratorio donde estudiar las contradicciones y conflictos que se generaron en torno a la actividad minera durante el período colonial. La crisis minera de fines del siglo XVIII desató tensiones y a su vez evidenció estrategias que pusieron de manifiesto posiciones de rechazo a la disciplina y a los abusos que representaba la explotación de los azogueros, por parte de la población indígena de esta región surandina. En este trabajo vamos a analizar estas diferentes posiciones y estrategias a través de un interesante expediente surgido del conflicto entre los dos azogueros de Carangas y el subdelegado Marín, quien contó con el apoyo de la mayoría de las autoridades indígenas del partido.

Vamos a centrarnos especialmente en la vinculación de los carangas con la minería, pues desde que se descubrieran las famosas minas en la doctrina del Turco a principios del siglo XVII (Gavira 2008; Medinaceli 2012), la población tuvo en este rubro un recurso importante para conseguir numerario con que pagar sus cargas tributarias. La población, mayoritariamente indígena y compuesta por aymaras (en mayor proporción) y urus, estaba asentada durante el siglo XVIII en las siguientes doctrinas: Huachacalla, Andamarca, Corque, Chuquicota, Huayllamarca, Totora, Cuaraguara y $\operatorname{Turco}^{2}$ (Figura 1). La organización interna de los carangas está basada en

\footnotetext{
I Facultad de Historia, Universidad Michoacana de San Nicolás de Hidalgo. Avenida Francisco J. Mujica s/n, Ciudad Universitaria, C.P. 58030, Morelia, Michoacán, México. Email: cgaviram@hotmail.com

2 Estos nombres se ven a veces sometidos a variaciones en las fuentes coloniales dependiendo de su transcripción del idioma aymara y uruqui1la. Algunas veces aparece Chuquicota o Choquicota, Guallamarca o Guaillamarca, Curaguara o Curahuara.
} 


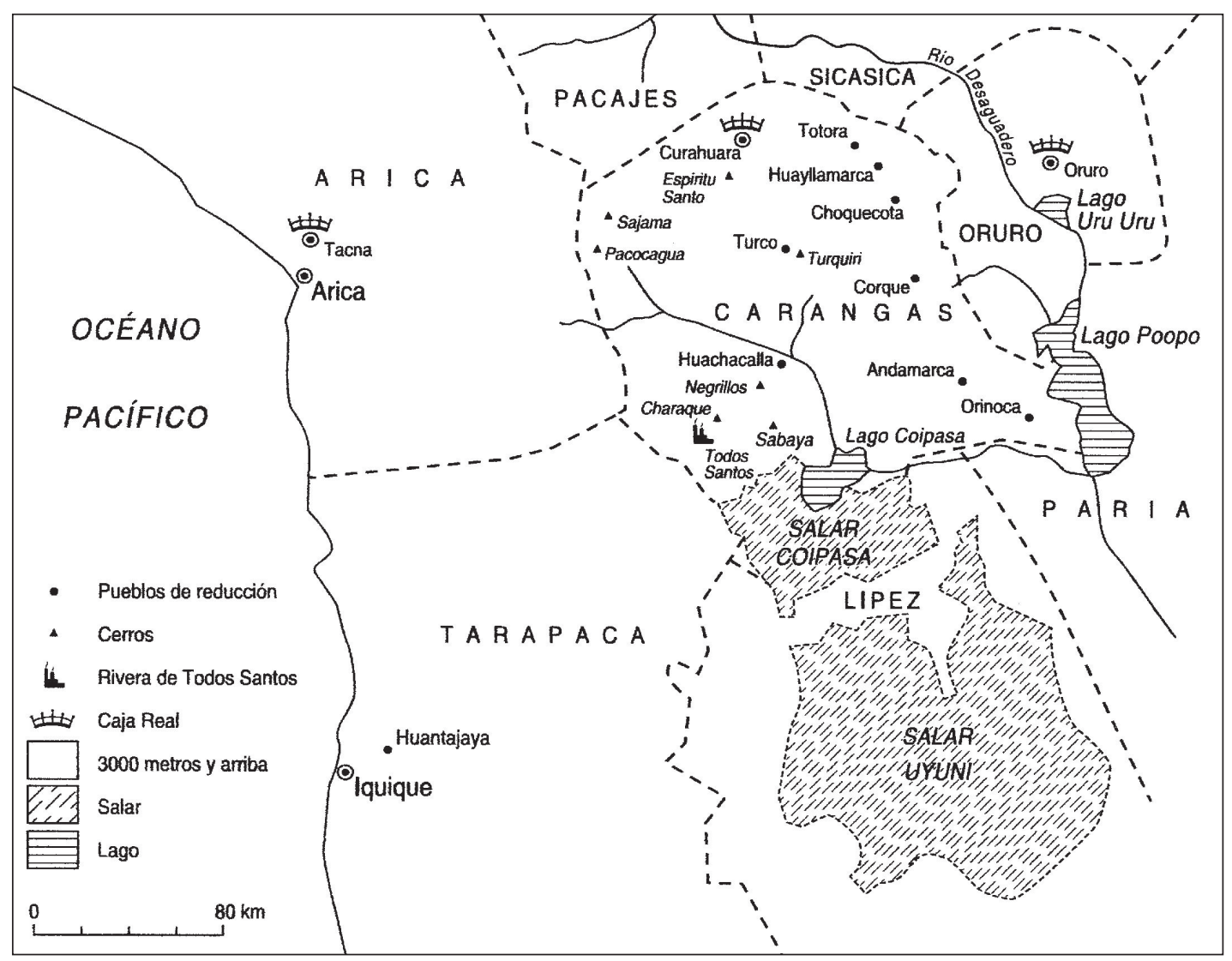

Figura 1. Mapa del Corregimiento de Carangas. Siglo XVIII.

los ayllus como grupo de parentesco vinculado a un antepasado común que controla un territorio determinado y cuyos representantes son los curacas o caciques. Estos grupos además, pertenecen a dos parcialidades diferentes denominadas Aransaya y Urinsaya. Es decir, cada repartimiento o pueblo estaba constituido por ayllus de las dos parcialidades, y cada ayllu estaba compuesto por estancias o residencias de familias extensas (Riviere 1982).

La dificultad para evaluar la producción de plata de este distrito al iniciarse la contabilidad de la Caja Real, ${ }^{3}$ ya reflejaba movimientos y registros de plata que respondían a las estrategias de los azogueros de Carangas y Huantajaya frente a sus propias necesidades y la política minera borbónica. Es decir, resulta complicado precisar

3 La Caja Real de Carangas se abrió en 1652. Se pensaba que la apertura de esta institución ayudaría a que no saliera tanta plata de contrabando por la costa de Arica. la producción y adjudicarla a un centro concreto, pues además de la plata que salía por la vía del contrabando, los azogueros, comerciantes y autoridades registraban el mineral en distintos lugares según conveniencia. En trabajos ya publicados (Gavira 2005 y 2008) hemos presentado la gráfica de la estimación de la producción de plata y analizado sus flujos y reflujos, señalando finalmente la crisis minera del partido de Carangas y el definitivo cierre de la Caja Real en 1804 (Figura 2).

La producción de plata en Carangas fue decayendo durante las últimas décadas del siglo XVIII. La causa de este declive no era de origen externo -como pudiera ser la sublevación indígena de 1781 - se trataba de un problema interno, específicamente minero, que requería grandes inversiones para desaguar las minas y posibilitar las labores allí donde el mineral seguía siendo rentable. Pero los mineros no pudieron o no quisieron asumir este riesgo 


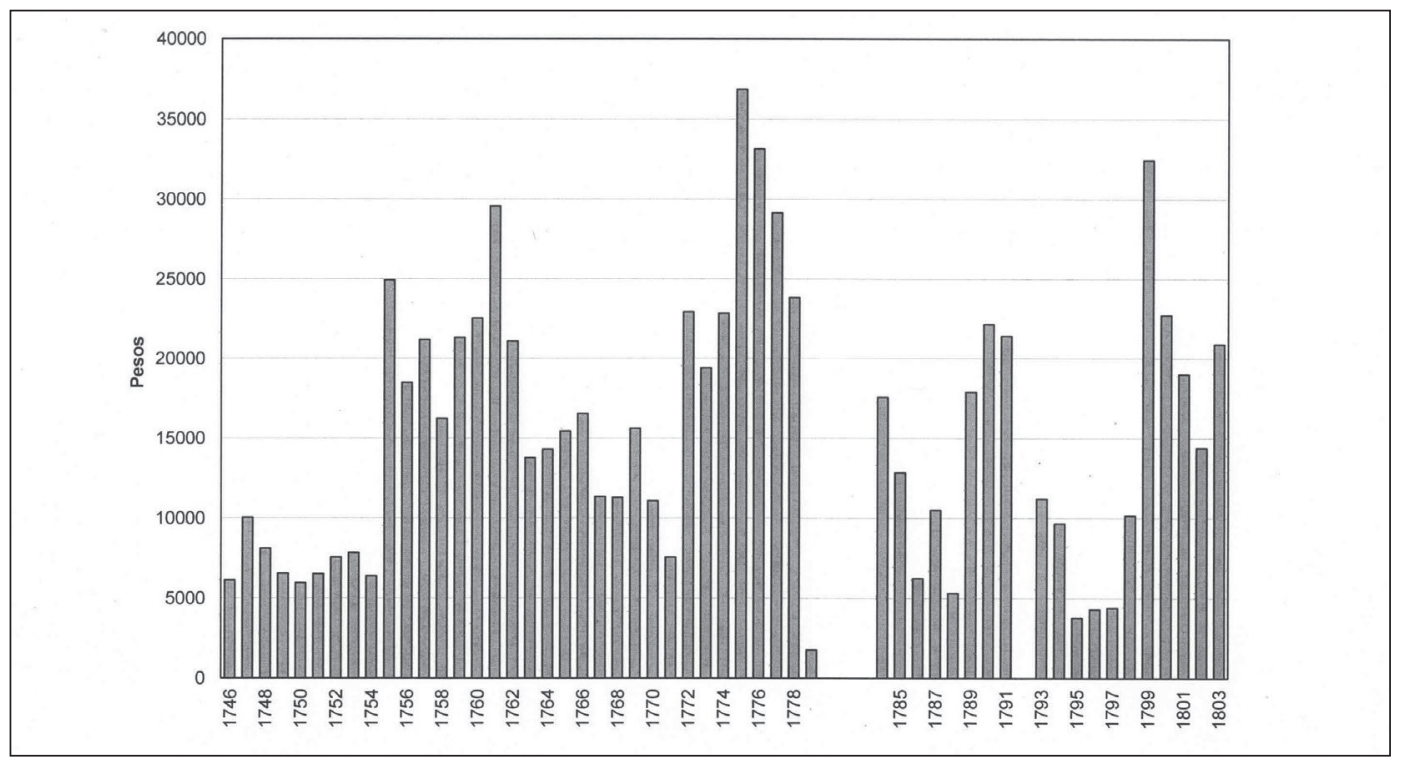

Figura 2. Impuestos sobre la plata. Caja Real de Carangas, 1746-1803 (AGI, Charcas 637, año 1784).

y en muchos casos se trasladaron hasta los centros extractivos en auge como Huantajaya. En Carangas quedó un reducido número de azogueros y de rescatistas (estos últimos generalmente indígenas y mestizos), que controlaban la actividad minera. La disminución de los recursos y la competencia por su control entre este pequeño grupo, en el cual se incluía la burocracia, originó conflictos y tensiones que llegaron hasta la Audiencia de Charcas en varias ocasiones. Generalmente, estas pugnas se desataban al producirse un desequilibrio en el estatus consolidado, por ejemplo cuando apareció el nuevo subdelegado, el cual emprendió negocios por su cuenta entrando en competencia con los dos azogueros del partido. En medio de este conflicto se encontraba la población tributaria que supo sacar provecho a la situación de enfrentamiento entre la máxima justicia de la jurisdicción y los azogueros. Los tributarios de Todos Santos habían comprobado cuán perjudicial era la asociación de los azogueros y las autoridades locales y, con la llegada del subdelegado y su negocio de rescate de plata, consiguieron cierta independencia como observaremos a partir del análisis de este conflicto.

Es difícil encontrar fuentes que traten de forma específica el tema de la mano de obra y condiciones laborales de los indígenas empleados en la actividad minera durante la colonia. Los testimonios indígenas con los cuales con- tamos sobre Carangas están incluidos dentro de los conflictos entre los mineros y la burocracia, por lo cual deben ser analizados con cierta precaución. Era frecuente que los implicados en una denuncia presentasen testimonios de las autoridades indígenas para reforzar las distintas acusaciones, ya que la justicia era especialmente sensible a este tema. Sin embargo disponemos de evidencias que manifiestan la resistencia de los carangas a emplearse como mano de obra minera ante los abusos cometidos por mineros y azogueros. Los malos tratos recibidos y el pago de un salario escaso fueron motivos suficientes para que los tributarios de Todos Santos prefirieran mantenerse en esta actividad de forma independiente.

Algunos estudiosos, sin embargo, han sostenido que el trabajador minero de México era privilegiado en cuanto a su salario. ${ }^{4}$ Lejos de esa situación, en los centros mineros

4 Brading (1975) afirma que en Nueva España en el siglo XVIII, los trabajadores mineros "lejos de haber sido los peones oprimidos que la leyenda nos presenta constituían una fuerza laboral libre, bien pagada y geográficamente móvil". Hace referencia al salario minero de cuatro reales diarios a diferencia de los dos reales (más comida y tierra) de un trabajador de hacienda. Las levas y repartimientos de indios fueron más significativos en el centro de México y, según este autor, disminuyó durante el curso del siglo XVIII. Sin embargo, Brígida von Mentz (1988: 23-45) recoge 
altoperuanos de los que tenemos conocimiento (Potosí, Oruro, Aullagas y Carangas), los trabajadores sufrieron en su mayoría abusos y sobre-explotación durante la segunda mitad del siglo XVIII. Enrique Tandeter (1992) ya hizo referencia a la importancia de la renta mitaya en el Cerro Rico de Potosí. 5 En Oruro (Gavira 2000 y 2005) hemos advertido también un empeoramiento en las condiciones de la mano de obra a fines del período colonial que se tradujo en una denuncia de los trabajadores de ingenios ante la Audiencia de Charcas en 1793. En Aullagas (Gavira 2013) tenemos noticas de los guatacos, sistema de coacción de la población para trabajar con ciertos azogueros coludidos con las autoridades locales. En el caso de Carangas, encontramos también testimonios de los abusos y la violencia de los azogueros, ante lo cual los indígenas optaron por diferentes estrategias de resistencia, adoptando diferentes formas según las circunstancias. Como sugiere Stern (1990), los patrones de resistencia andina incluían conductas tan diversas como la fuga, las batallas legales, motines locales, hasta la guerra insurreccional. Los tributarios de Todos Santos optaron en principio por la fuga y el abandono de sus casas, para después aliarse con la burocracia (el subdelegado), minando de esta manera la estrecha alianza entre los poderes locales de azogueros y corregidores.

\section{* El subdelegado Marín y su actividad de RESCATADOR DE MINERAL}

En 1783, una vez pacificada la región del Alto Perú, se pusieron en marcha las reformas administrativas cuyos objetivos principales consistían en racionalizar y hacer más efectiva la administración y explotación colonial. La premura por la implantación de las Ordenanzas de Intendencias en el virreinato del Río de la Plata fue la sublevación indígena de 1781, como también el intento de evitar los abusos de los corregidores que habían provocado estos movimientos rebeldes (Golte 1980). El establecimiento de las intendencias con sus nuevos funcionarios acababa con la detestada figura del corregidor y los repartos de mercancías, sustituyéndolo

la protesta de los campesinos que eran reclutados para el trabajo en las minas donde recibían malos tratos y bajos salarios.

5 Sugiere que la recuperación de Potosí en la segunda mitad del siglo XVIII, se sustenta principalmente en la sobreexplotación de los trabajadores forzosos o mitayos (Tandeter 1992). por el subdelegado. Pero en muchos casos, este nuevo cargo supuso la repetición de los comportamientos y manejos ya conocidos, que no se alejaban mucho de la situación anterior. Encontramos numerosas evidencias en los expedientes coloniales de los virreinatos del Río de la Plata (Gavira 2005a) y del Perú (Sala y Vila 1996) que recogen protestas y denuncias por un importante número de subdelegados que continuaban con el reparto de mercancías. Los requisitos para ser nombrados subdelegados eran un poco confusos, se requerían personas hacendadas, es decir con recursos, pero que estuvieran dispuestas a salir de su provincia para ejercer un empleo sin sueldo (Gavira 2013b). Según los intendentes, esto limitaba mucho la oferta de postulantes, ya que la prohibición de comerciar les dejaba con un $4 \%$ de la recaudación de los tributos, que se reducía después de pagar el 1\% al recaudador (Acevedo 1992). Precisamente la obtención de recursos fue uno de los motivos por los que se denunció al primer subdelegado que llegó a Carangas en 1784, Juan Dionisio Marín. El recién llegado suponía una agresión para los intereses de los dos mineros más importantes del asiento, que no estaban dispuestos a aceptar a un nuevo competidor. En 1785 Juan Sigler Campero, dueño de minas e ingenios, y Manuel Zorrilla, igualmente azoguero en el partido de Carangas, denunciaron al subdelegado Juan Dionisio Marín por realizar negocios rescatando mineral. Ambos montañeses, originarios del valle de Soba en las montañas de Santander, se aliaban para acusar al subdelegado ante la Audiencia de Charcas.

Manuel Zorrilla había llegado a Carangas poco antes de la muerte de su primo, ${ }^{6}$ el minero y azoguero Antonio Zorrilla que había ejercido de corregidor y que murió en 1777. Durante algún tiempo, que no podemos precisar, Manuel estuvo de administrador en el ingenio de su primo, del cual fue heredero. Las propiedades de Antonio, un ingenio en la ribera de Todos Santos y una mina en el cerro del Charaque, fueron embargadas para pagar las deudas contraídas con la Real Hacienda, por lo cual no pudo recuperarlas hasta 1782. Tres años más tarde, Manuel entraba en pleito con un indio que había encon-

\footnotetext{
6 En algunas fuentes aparece como hermano y en otras como primo. Nos inclinamos por el parentesco de primo porque ambos se denominaban Manuel, los dos se apellidaban Zorrilla de San Martín y provenían del Valle de Soba (Cantabria).
} 
trado unas barras robadas mientras fue administrador del ingenio, y que recuperó sin hacer caso al subdelegado que le exigía entregarla a la Caja Real para terminar de pagar las deudas de Antonio (ABNB, Minas, vol. 96, $n^{\circ} 18$, año 1785). Este desacuerdo fue simultáneo al pleito de los dos azogueros con el subdelegado.?

Los dos azogueros acudieron ante la Real Audiencia de Charcas a principios de 1785 denunciando los perjuicios que les ocasionaba el subdelegado Marín, el cual se dedicaba a repartir cantidades de dinero entre los indios con la obligación de que éstos lo devolvieran en marcos de plata, abonados al precio de seis pesos cuatro reales. Declaraban que con ello fomentaba el juqueo o robo en sus minas y el consiguiente destrozo de los puentes. Por tanto denunciaban al subdelegado por actividades ilícitas y perjuicios contra sus propiedades. Los azogueros decían haber invertido mucho en sus actividades después de la destrucción que produjo la sublevación indígena de 1781 y que ahora se veían obligados a abandonar su trabajo. Como prueba del rescate que efectuaba el subdelegado decían que el monto de los tributos lo cobraba en dinero que invertía en comprar barras y pastas de plata a los indios, las cuales eran utilizadas para el pago de este impuesto en la Caja Real. De esta manera el subdelegado estaba negociando con el caudal de la Real Hacienda. Como apoyo del perjuicio que representaba la actitud del subdelegado a los indios, presentaron el testimonio de Bartolomé Choque, quien sostenía que Marín tenía tiranizados a los indios y que el reparto de dinero lo hacía bajo coacción (ABNB, Minas, vol. 96, n 20, año 1785).

Marín en su defensa dijo que tomó posesión de su cargo en julio de 1784 y que inmediatamente mandó a Tarapacá cinco mil pesos de su propio capital para rescatar plata, puesto que el mineral de Carangas estaba "arruinado muchos años ha". Argumentaba que las minas de estos dos azogueros estaban aguadas y que "no hay en el mineral una mina útil que pudiera facilitar el rescate".

\footnotetext{
7 Según Manuel Zorrilla, cuando él administraba el ingenio de su primo se perpetró el robo de unas barras de plata. Él responsabilizaba al mayordomo José de Covarrubias, al cual "creyendo hombre de bien" le dejaba las llaves. Por este motivo, él mismo tuvo que reponer de su bolsillo la cuantía de lo robado. Después de algunos años, un indio encontró las barras enterradas en un paraje cercano (ABNB, Minas, vol. $96, \mathrm{n}^{\circ} 20$, fs. $382 \mathrm{v}-383$ ).
}

Decía que había rescatado algunos marcos sin ninguna malicia y a súplica de los interesados, y que no era posible incitar al robo en la minas de Sigler porque estaban aguadas y sin labor. Argumentaba que la enemistad de los dos azogueros procedía de haberse negado a prestarles dinero y a que sacasen azogues de la Caja Real sin fianzas. Por último, afirmaba que las 31 barras que llevó Matías González de Cosio al Banco de San Carlos en Potosí fueron compradas con caudal suyo. Se defendía de la denuncia del indio Bartolomé Choque diciendo que era causada por su resentimiento, ya que lo había sustituido como cobrador por sus excesos y no tener título alguno. Presentó para su apoyo el testimonio de distintas autoridades indígenas de Carangas que decían que Marín tenía un comportamiento correcto y los trataba con justicia (ABNB, Minas, vol. 96, nº 20, año 1785, s/f).

Es muy posible que los dos azogueros estuvieran resentidos con Marín porque el anterior corregidor que había sido su socio, Antolin Chavarri, les había beneficiado en todo lo posible, hasta el punto de registrar en el libro de la Caja Real pagos que no se habían efectuado por parte de Sigler, y de favorecer a Zorrilla con el depósito de las propiedades de su primo Antonio, sin ingresar ningún dinero para cubrir la deuda pendiente. ${ }^{8}$ Sin embargo, al llegar Marín tomó diligencias que perjudicaban a los dos azogueros. En 1784 efectuó el embargo de un trapiche y una mina en Todos Santos pertenecientes a Sigler para el pago de una deuda que tenía pendiente con la Real Hacienda del remate de los bienes del corregidor Mateo Ibáñez y del contador Manuel Guemes, ambos asesinados durante la rebelión (AGI, Charcas, 637, año 1784). Esta actitud del subdelegado seguramente provocó la enemistad de los azogueros que se encontraron frente a un funcionario que no estaba dispuesto a encubrir sus negocios fraudulentos con la Real Hacienda.

El subdelegado Marín estaba rescatando plata sin lugar a dudas, porque en 1785 registró en la Caja Real 1.119 marcos, más del $8 \%$ del total de los registros de ese año, además de lo que envió directamente al Banco de San Carlos (ABNB, Minas, vol. 92, no 20, año 1785, f. 363). Lo que no podemos precisar (Gavira 2005) es cuánta

8 Antolín Chavarri estaba casado con la orureña Isabel Sánchez de Losada. Suponemos que estaba asentado en Oruro, pues allí encontramos a Isabel como viuda en 1796. 
plata provenía de Carangas y cuánta de Huantajaya (Tarapacá). Definitivamente estaba probado que rescataba plata en Carangas, pero de lo que no había testimonios era de que ejerciera coacción entre los indígenas para hacer este negocio. La comisión para investigar el caso se le dio en un principio a Simón Romano, vecino de Oruro, el cual se encargó de recoger los testimonios de trece vecinos. Entre los testigos había dos mestizos, siete españoles y cuatro indios.

Todos los testigos confirmaban que el subdelegado rescataba plata de los "jucos y vecinos de este asiento", pero ninguno afirmó que esto se hiciera bajo coacción o violencia. Entre los nombres de las personas que habían entablado este negocio figuraban: el segunda persona de Todos Santos Tomás Romano, José Condori, Carlos Cusiguaman, don José y Santiago García Manzano, Isidro Soto, Juan de Dios Arco y don Ambrosio Cerezo Alderete. El segunda de Todos Santos respondió que él no sabía que Marín repartiese dinero a los vecinos de este asiento, pero sí sabía que compraba marcos de plata y

"[que] siendo segunda de Todos Santos también vino a pedirle plata para el mismo efecto en distintas ocasiones, la cual repartía entre los indios y demás del pueblo mencionado que ocurrían a él con noticia que tenía de sacar dinero perteneciente a don Juan Marín para el efecto, los cuales marcos juntos por estas gentes los entregaban a él y al mencionado don Juan Marin y que el alcalde del dicho pueblo no sabe les haya repartido dinero alguno" (ABNB, Minas, vol. 96, nº 20, año 1785 , f. 350).

El ensayador José García Manzano dijo que él había sido fiador de algunos de los sujetos a los que el subdelegado adelantó dinero para ser devuelto en marcos de plata. También confirmó que los indios pagaron sus tributos en moneda, pero que Marín lo había hecho en monedas y barras de plata. En el caso de Juan de Dios Arco ${ }^{9}$ parece que el compromiso con el subdelegado era mayor, pues en una de las preguntas se pedía confirmación sobre el despojo que éste había hecho a Zorrilla de una mina en el cerro de Espíritu Santo "por orden del dicho don Juan Marín”, mientras el azoguero estaba en Chuquisaca. La

9 En 1791 este minero formaba compañía con Juan José de los Olivos para explotar una mina en Santa Rosa (Tarapacá) (Villalobos 1967: 153). respuesta de Juan de Dios fue que Zorrilla la dejó con dos peones y pocos avíos y que después de quedar abandonada empezaron a trabajarla los jucos, y que entonces fue cuando él la pidió por despoblada, pero que sacó muy poco beneficio de esta mina (ABNB, Minas, vol. 96, $\mathrm{n}^{\circ}$ 20, año 1785, f. 357).

Como se deduce de la relación de los testigos y las repuestas, la mayoría estaban implicados en los negocios de Marín, por tanto difícilmente darían testimonios que fueran en contra de sus intereses. Generalmente, en cualquier asiento minero era bienvenido un comerciante rescatador con dinero disponible, pues la mayoría de los vecinos sacaban provecho. Algunos de estos vecinos escribieron una carta al intendente de Charcas defendiendo al subdelegado porque decían que todo era "un complot para poner a Juan Sigler en el gobierno del partido" (ABNB, Minas, vol. 96, nº 20, 1785, f. 378). Los firmantes eran Leandro y Andrés Ozio, Gabriel Ledesma, José y Manuel García Manzano, Santiago Manzano y Carlos Vilca. Los hermanos García Manzano eran españoles y posiblemente descendientes del maestre de campo Don Francisco García Manzano, azoguero en Carangas durante la primera mitad del siglo XVIII. José era ensayador y fundidor en la Caja de Carangas. Los hermanos Ozio eran comerciantes en el asiento y habían recibido dinero de Marín, al igual que Ledesma. Nos parece muy interesante que el ensayador José García Manzano fuera denunciado ese mismo año por un fraude con las pesas utilizadas en la fundición de las barras de plata que se registraban en la Caja Real. Es muy posible que los autores de la denuncia fueran los dos azogueros. Todas las armas eran válidas en estos conflictos locales, donde todos se conocían y sabían cómo utilizar las leyes en función de las rencillas particulares. ${ }^{10}$

El conflicto creó dos partidos en la provincia: los que estaban a favor y en contra del subdelegado. Los oficiales reales reconocen que repartió dinero entre la población para ser devuelto en plata y que además también repartió botijas de vino "que él decía que no obligaban a nadie". Terminaban excusando este comportamiento por el escaso beneficio que reportaba el cargo de subdelegado. Los que apoyaban a los dos azogueros eran

\footnotetext{
${ }^{10}$ La denuncia fue realizada por los mineros en 1784, según los datos que aporta Saguier (1992) pero no se precisan nombres.
} 
Antolín Chavarri, anterior corregidor y socio de Zorrilla, y Bartolomé Choque. Los dos mineros tenían una relación especial con Chavarri con el cual compartían negocios y se beneficiaban de su trato favorable. Juan Sigler en 1784 todavía debía a la Caja Real el remate de los bienes embargados al corregidor Mateo Ibáñez y al contador Juan Manuel Guemes. Según las anotaciones de los libros de la Caja Real, Antolín Chavarri "que corrió solo con estas Cajas, las dio como efectiva, y no lo era según parece de la relación jurada de deudas" (AGI, Charcas, 637, año 1784, s/f.). Manuel Zorrilla también se benefició porque tomó posesión del ingenio de su primo en condiciones sospechosas, pues a pesar de la deuda que tenía con la Real Hacienda no ingresaba ningún pago en la Caja Real.

El proceso fue largo y duró más de un año. En principio, la Audiencia destituyó a Juan Dionisio Marín como subdelegado y nombró como interino al comisionado Simón Romano que era vecino de Oruro y administrador de la renta de tabacos. Marín recusó a Simón Romano ${ }^{11}$ como juez comisionado y entonces se nombró al alcalde de Oruro Miguel del Llano. En junio de 1785 se volvió a reponer a Juan Dionisio Marín como subdelegado porque "no se ha podido encontrar persona" que aceptase el partido de Carangas (ABNB, Minas, vol. $96, \mathrm{n}^{\circ} 20,1785$, f. $375 \mathrm{v}$.). ${ }^{12}$ En la resolución final de la Audiencia de Charcas se absolvió a Marín y a los azogueros se les impuso perpetuo silencio.

Los testimonios en que se apoyaba Marín nos sugieren algunas preguntas decisivas. Teniendo en cuenta que el informe de los dos visitadores de las minas decía que las minas de los azogueros estaban aguadas, concretamente la de Sigler; ${ }^{13}$ entonces ide dónde sacaba la plata que

${ }^{11}$ Simón Romano era vecino y minero en Oruro, fue administrador de correos y tabacos en Carangas, y en 1790 fue subdelegado de Oruro.

12 Marín estuvo en Carangas durante 1786. También ejerció de tesorero interino ese mismo año. Él pidió en repetidas ocasiones abandonar Carangas debido a su mala salud, pero no se lo aceptaron hasta el final del pleito.

13 La visita realizada a las minas de Sigler fue encargada a Gabriel Ledesma y Tomás Garmendia. Estos se trasladaron hasta el cerro de Todos Santos, a la mina de San Andrés y dijeron que se encontraba "toda ella casi llena de agua" (ABNB, Minas, vol. 96, n²0, f. 360 ). se estaba beneficiando en su ingenio? Es muy posible que los azogueros consideraran al subdelegado un competidor a la hora de rescatar el mineral que ellos estaban beneficiando en sus ingenios, y que procedía de los buscones e indios que recogían mineral de los desmontes y de las minas abandonadas. Tal vez, como decían los perjudicados, se estaba "desviando las gentes que habíamos de dedicar a la saca y beneficio de metales y conspirándola toda a nuestra total ruina" (ABNB, Minas, vol. $96, n^{\circ} 20,1785$, f. 299).

El año de 1784, el total de la producción de plata registrada fue de 17.958 marcos. Sigler no realizó ningún registro de plata en la Caja Real y Zorrilla tan sólo 72 marcos. En realidad, Sigler no volvió a registrar plata bajo su nombre en la Caja de Carangas, aunque no podemos saber si lo hizo bajo testaferro o se encargaba Zorrilla de hacer los registros. Es muy posible que, al ser deudor de la Real Hacienda, no lo hiciera para evitar que le embargasen la plata. Sin embargo, Zorrilla también era deudor $y$, aunque el subdelegado había intentado embargarle en 1785 un barretón, la Audiencia mandó que se lo devolvieran. Es muy probable que la producción de plata durante 1784 y 1785 se viera fomentada por el capital invertido por el subdelegado. El descenso de 1786 pudo deberse a la retirada de las inversiones de Marín que estaba esperando el permiso de la Audiencia para abandonar el partido cuanto antes, pues había enviado continuas peticiones en octubre y noviembre de 1785 para que le dejasen salir de Carangas e instalarse en un lugar más benigno para su salud.

Los diferentes testimonios que contiene el expediente nos sugieren que se trata de un conflicto por los recursos del asiento: bien por el mineral que obtenían buscones y jucos o bien por la mano de obra, ya que los indígenas podían conseguir dinero a través del rescate de Marín sin necesidad de contratarse como trabajadores. El subdelegado a través del rescate estaba monopolizando y controlando una gran parte de la producción de plata de Carangas, que provenía de la minería de pequeñas proporciones que estaba en manos de los indígenas. Mientras los dos azogueros contaron con la complicidad del anterior corregidor todo fue bien, pero con la llegada del nuevo subdelegado había que recomponer el reparto de poder y excedentes, y el recién llegado tenía pretensiones de hacer negocios por su cuenta. 


\section{* La resistencia de los tributarios de} Todos Santos

En el conflicto entre el subdelegado y los azogueros se presentó una queja de los tributarios del pueblo de Todos Santos contra Manuel Zorrilla. Parece que no era la primera vez que se quejaban del trato que éste impartía. En esta denuncia exponían los bajos salarios que el azoguero pagaba a los trabajadores:

"Desde que dicho Manuel Zorrilla principió a trabajar estas minas padecemos toda la comunidad grande desdicha y calamidad porque a más de alistarnos éste para peones con un excesivo rigor, el alivio que nos da para la semana que contiene nueve mitas [turnos] se reduce a libra y media de coca y doce reales de plata, estos reales apenas equivale a la paga de seis mitas..." (ABNB, Minas, vol. 96, nº 18, año 1785, f. 271v).

Continuaban denunciando el escaso pago que daba a los bajadores del metal. La baja desde la mina hasta el ingenio de un cajón de cincuenta quintales que costaba dos pesos, la pagaba el azoguero a 12 reales y les daba la mitad de este valor en coca. En esas condiciones no estaban dispuestos a trabajar, pero el azoguero los amenazaba a fuerza de "trompadas, palos y azotes". También sufrían otras extorsiones porque decían que el terreno donde estaba instalado el pueblo de Todos Santos había sido comprado por el minero (suponemos que se trataba del propietario Antonio Zorrilla). Se quejaban de que obligaba a los tributarios a prestarle diferentes servicios y no les pagaba, alegando:

"[... que nos la comunidad debemos contribuirle cada año alguna cantidad del arriendo de las tierras que poseímos por razón de que en calidad de minero ha comprado de su Majestad el ingenio donde reside y todo el territorio del pueblo dicho de Todos Santos" (ABNB, Minas, vol. 96, nº 18, año 1785, f. 272v).

No sabemos cómo ni cuándo estas tierras fueron compradas por el azoguero y nos parece muy extraño que la comunidad vendiese el territorio donde tenía su residencia. Es muy posible que la compra se realizara bajo presión cuando Antonio Zorrilla era corregidor de Carangas. Para el azoguero era un buen negocio, en cuanto que tenía a su disposición los mecanismos para coaccionar a los tributarios y obtener mano de obra semi gra- tuita. Sin embargo, los tributarios de Todos Santos se quejaban de los abusos cometidos por Manuel, el cual estaba administrando este ingenio desde la década de los setenta.

Los tributarios optaron ante las presiones por abandonar sus tierras y salir hacia otros parajes, ya que no encontraron amparo en la justicia. El problema era que, hasta entonces, los anteriores corregidores Mateo Ibáñez y Antolín Chavarri estaban asociados con los Zorrilla, por lo cual sus quejas no eran estimadas. Después de la huida de los tributarios, el azoguero para disponer de trabajadores acudió a los urus (chipayas), los cuales también manifestaron su oposición huyendo del ingenio. Zorrilla tomó la determinación de encerrar a los chipayas en el ingenio:

"[...] tenía a los dichos chipayas encerrados en un cuarto por parte de la noche, y a poco que el sol salía, ya los echaba al buitrón, pero con toda esta seguridad en una noche rompiendo la ventana del cuarto en que estaban encerrados se huían siempre"(ABNB, Minas, vol. 96, n⿳ำ 18 , año 1785, f. 273).

Manuel Zorrilla se defendió de estas acusaciones diciendo que el alcalde de Todos Santos había sido manipulado por el subdelegado. Pero también se unieron a la defensa de Marín el resto de autoridades indígenas de Carangas. El alcalde de Todos Santos decía que con la llegada de Juan Dionisio Marín habían encontrado justicia y habían vuelto al pueblo. El alcalde y los tributarios preferían aliarse con él y entrar en el negocio del rescate de plata antes que emplearse con Zorrilla. Nunca pudo probarse que el subdelegado realizara este negocio bajo coacción $y$, en todo caso, a los tributarios les permitía conseguir dinero sin tener que someterse a la disciplina impuesta por los azogueros y a los abusos que éstos les impartían. Tampoco se pudo probar que fomentara el juqueo o robo de mineral porque los testimonios aseguraban que había gran cantidad de minas abandonadas en Carangas, donde los indígenas recogían el mineral.

La coacción para reclutar trabajadores aumentaba en los tiempos de crisis. En Oruro durante las dos últimas décadas del siglo XVIII, tenemos evidencias de abusos y violencia en el reclutamiento y en las condiciones laborales. También los trabajadores de ingenios se quejaban de ser llevados con engaños hasta las instalaciones y de 
ser encerrados en ocasiones en los buitrones. ${ }^{14}$ La falta de rentabilidad de las empresas mineras era uno de los motivos para el pago de salarios escasos y horarios excesivos. Estas condiciones provocaban la resistencia de los indígenas a emplearse como mano de obra y en contrapartida aumentaba la violencia en el reclutamiento y retención de los trabajadores (Gavira 2000).

Pero en el caso de Huantajaya, en pleno auge minero, también se produjeron problemas para encontrar mano de obra disponible, porque al duro trabajo en las minas se sumaba el grave problema de la escasez de agua y el encarecimiento de los alimentos. La solución para atraer a los trabajadores hasta las minas fue la alanoca o adelanto de productos para endeudar al operario. ${ }^{15}$ En algunos casos los trabajadores se marchaban dejando la deuda pendiente, pero los mineros lo compensaban con el pago del salario en mercancías a subidos precios. En una de las cláusulas de un contrato entre mineros de Huantajaya, se estipulaba lo siguiente:

"[...] que no siendo posible pagar a los peones y más operarios en plata sellada semanalmente por la dificultad que hay en proveerse de este género en esta provincia, se ejecute, según lo establecido, que es parte en plata y parte en géneros, dándoseles los que pidiesen a los precios corrientes que dejan un ciento por ciento, según las compras que se hubiesen hecho, atendiendo lo mucho que perderá la compañía con los operarios y peones que murieren o se ausentaren" (Villalobos 1967: 207).

El poderoso minero de Huantajaya José Basilio de la Fuente consiguió en 1758 que el virrey conde de Superunda le concediera una mita de 50 trabajadores sacados de los pueblos de San Lorenzo de Tarapacá y de Sibaya. Los

14 En 1793 los trabajadores de los ingenios de las riberas de Oruro y Paria acudieron ante la Audiencia de Charcas para denunciar a los azogueros por los abusos y coacciones a los que eran sometidos, entre otras cosas se quejaban de las levas forzosas y de ser encerrados en los ingenios (Gavira 2000). En Zacatecas (México), Bakewell (1976) hace alusión al endeudamiento y prisiones particulares para evitar la fuga de los operarios indios durante el siglo XVII.

15 Antonio O'Brien informaba que en el cerro de Huantajaya los trabajadores "son todos zambos, mulatos, mestizos, cholos y muy pocos indios". Describe la negociación de los trabajadores con los mineros para emplearse, cómo exigían una cantidad de productos en adelanto $y$, en muchos casos, no cumplían con el trabajo (AGI, Lima, 1351, año 1765). indígenas recurrieron ante las autoridades pidiendo que se les cambiara el trabajo en las minas por el trabajo en su ingenio de Tilivilca (Guarasiña), entre sus argumentos exponían el ardiente calor de Huantajaya y la escasez de agua y corta ración que se les daba a los trabajadores. Reclamaban también un "jornal en plata y en mano propia y no en otro efecto alguno" (Villalobos 1967: 220).

\section{^ Un mineral en manos indígenas: JUCOS Y BUSCONES}

Juan Dionisio Marín afirmaba que en Carangas no había "una mina útil" y que por tanto no se realizaba labor de extracción por parte de ningún minero, incluido Sigler y Zorrilla. También aludía a que en el partido, como en cualquier centro minero, había jucos pero afirmaba que esta actividad era muy generalizada y la única.

"Lo cierto es que en todos los minerales y en el de Carangas siempre ha habido jucos o capchas, y que en éste hay sobre mil bocaminas en los cerros de Negrillos, de San Antonio, de Espíritu Santo y otros, en cuyos desmontes y ruinas rescatan los jucos llampos y puntas de metal que dejaron los antiguos, de lo que sacan sus onzas de plata y no de las minas aguadas de Sigler y Zorrilla, y estas las venden a los rescatiris públicamente. Y sólo por acriminar a Marín les causa mucha novedad de que haya jucos, siendolo alli todos, por ser un mineral abandonado" (ABNB, Minas, vol. 96, nº 20, año 1785, f. 124).

Los jucos eran considerados ladrones de minas, aunque en este caso se trata más bien de buscones o gente que realizaban una actividad independiente que no contravenía ninguna ley al dedicarse a recoger desmontes o mineral en las minas abandonadas. ${ }^{16}$ No se alude en ningún

16 La definición de jucos de Rück (S. XIX) es la siguiente: "Los trabajadores que furtivamente entran a las minas abandonadas por algún tiempo, para explotar el mejor metal que encuentran con grave perjuicio de los dueños y del mismo laboreo por el desorden con que verifican trabajos y por no extraer jamás caja alguna con lo cual poco a poco obstruyen toda la labor. En Potosí guardan cierto orden que algunas veces es acordado con el dueño de la mina y a vista de los mayordomos de éste, para impedir cualquier trabajo inconveniente y ruinoso. Los metales que explotan los jucos los suelen partir con el dueño de la mina, lo que no impide que se queden siempre con la parte más rica" (citado por Langue y Salazar-Soler 1992: 301). 
momento a un colectivo como ocurría con los capchas de Potosí, los cuales actuaban en grupo y a veces bajo concierto con el dueño de la mina para compartir el mineral (Tandeter 1992; Platt 1996)

Otro testimonio de los oficiales reales decía que la gente de este partido era muy pobre por causa de la crisis minera y que eran las indias las dedicadas a la búsqueda del mineral. Suponemos que podría tratarse de una actividad complementaría para adquirir recursos o porque los hombres estaban durante mucho tiempo fuera ocupados en sus trajines y viajes:

"[...] los que se dedican comúnmente a este trabajo son las indias, que obligadas de la necesidad recogen hasta las tierras de las calles y lavándolas en el río sacan a fin de la semana unas pocas onzas de plata que venden para su sustento, y las más veces ya tienen tomados de los rescatiris los efectos que pagan con lo mismo que sacan, a que se agrega que las minas están abandonadas hace mucho tiempo y por consiguiente sin dueños conocidos" (ABNB, vol. $96, n^{\circ} 20$, año 1785, f. 125).

Las fuentes más tempranas que conocemos sobre las diferentes labores mineras que realizaban las mujeres en los centros andinos datan de fines del siglo XVI y de principios del siglo XVII. Luis Capoche en su relación de la villa de Potosí (1585) hace mención a las mujeres que se dedicaban a tamizar el mineral, las cuales ganaban un salario de dos reales. ${ }^{17}$ Una descripción de la villa y minas de Potosí, de autor anónimo, escrita en 1603 hace alusión a las mujeres y los niños ocupados en pallar o escoger mineral:

"[...] ocúpanse en pallar, que es buscar piedras y tierras y granzas de metales sueltos que están en la superficie de la tierra, de indios muchachos y mujeres que viven de esto más de mil y éstos venden lo que juntan por cargas, que conforme es el metal es el precio, y averiguado se sabe que no hay personas de estas que cada día no gane más de un peso" (BB, Add. Ms. 20.999, año 1603, f. 274).

\footnotetext{
17 "Molido que está el metal, lo ciernen con unos cedazos de telas de alambre y hacen la harina tan delgada como los [cedazos] comunes de cerdas. Y muchas personas ciernen con ellos porque se amañan mejor las indias que con los que están armados con los que ciernen los hombres; y por falta que hay de indios se mingan las mujeres y muchachos y les dan dos reales..." (Capoche 1959: 122-123).
}

Además de esta labor también había mujeres ocupadas en el beneficio de las lamas, en el acarreo de leñas y estiércol y de "dar fuego a los cajones de metal". Como señala Brooke Larson (1983), las mujeres indias desde el principio se vieron obligadas a tomar un papel activo en la reproducción familiar debido a que el salario minero de Potosí no era suficiente para el sustento de la familia mitaya. Comercializando la korpa (pago en mineral) o buscando en los desmontes, consiguieron hacerse con el mercado al menudeo de mineral que vendían a los rescatistas o a los mismos dueños de ingenios (Assadourian 1979). En el caso de Carangas también eran las mujeres las que se dedicaban a esta labor, de manera que la división del trabajo aportaba más medios a la economía familiar. ${ }^{18}$

La venta del mineral les permitía obtener los productos no accesibles en su medio o conseguir dinero, aunque éste no siempre era preferido debido a las pocas opciones para comprar ciertos productos y su encarecimiento en este corregimiento tan apartado. Los recursos obtenidos por las mujeres a través de esta actividad permitían a los hombres la posibilidad de dedicarse a sus trajines en el valle sin tener que emplearse en las minas o ingenios. También podían vender su fuerza de trabajo en los valles, donde es muy posible que obtuvieran mejor salario que en los empleos mineros. Según un estudio de Jorge Hidalgo (1987), los salarios en las haciendas de Arica y Tarapacá oscilaban entre cuatro y seis reales diarios más la ración. Los tributarios de Todos Santos se quejaban de que Zorrilla pagaba menos de dos reales por día y un poco de coca.

Es muy posible que fuese exagerado el comentario de Marín al decir que no había ninguna labor de extracción en Carangas, aparte de los jucos. Pero por supuesto esta actividad no era la única en todo el partido. No tenemos datos suficientes para establecer el calendario de actividades de los carangas, pero sabemos que no siempre estuvo sujeto a las exigencias de la minería. En 1788, el subdelegado Pedro del Cerro decía en su informe que el año anterior algunas labores de minas habían parado por carecer de productos necesarios.

\footnotetext{
${ }^{18}$ También los indígenas mitayos adjudicados a Basilio de la Fuente pedían que les dejaran llevar con ellos sus mujeres e hijos (Villalobos 1967: 217).
} 


\begin{tabular}{|lr|lr|}
\hline \multicolumn{1}{|l|}{ Carangas } & \multicolumn{2}{l|}{ Tarapacá } & \\
\hline CACERES, José & $1,80 \%$ & ELORRIAGA, J.B. & $9,47 \%$ \\
\hline CACERES, Narciso & $1,80 \%$ & FUENTE, de la Fco. & $13,42 \%$ \\
\hline CANAVIRI, M. & $2,35 \%$ & GONZALEZ COSIO, M. & $22,50 \%$ \\
\hline CEREZO ALDERETE & $12,40 \%$ & MORALES, Gregorio & $20,51 \%$ \\
\hline ZORRILLA, Manuel & $1,52 \%$ & SALAZAR, R. & $8,60 \%$ \\
\hline & & PURI, Carlos & $5,50 \%$ \\
\hline Total: 4,597 marcos & $\mathbf{1 9 , 8 7 \%}$ & Total: 18,060 marcos & $\mathbf{8 0 , 0 \%}$ \\
\hline
\end{tabular}

Tabla 1. Procedencia y registradores de plata en el año 1790 en la Caja Real de Carangas (Gavira 2008: 61).

"El sebo estuvo muy carente, que en el trabajo de las minas se consume una porción muy considerable, pues en los meses de febrero, marzo y abril por su carestía dejaron de trabajar algunas labores. Para evitar este atraso voy a tomar la providencia que en los pueblos donde se cosecha en matanzas de carneros de la tierra para este tiempo no se los lleven a vender a los valles, y al precio de diez quintales en que lo mercan precisamente provean a este asiento dichos pueblos con porción señalada de quintales" (ABNB, EC, año $\left.1788, n^{\circ} 13, s / f\right)$.

El hecho de que los tributarios hubiesen preferido bajar el sebo a los valles en vez de destinarlo a los asientos mineros producía un claro desfase con las necesidades de las empresas mineras, las cuales quedaron desabastecidas en otoño, en meses de plena actividad. ¿Por qué se alteró el calendario habitual o se cambio la plaza de mercado para el sebo? No tenemos más referencias al respecto, pudo ser por motivos económicos: mejor precio de venta, o por motivos extraeconómicos: urgencia de otros productos de primera necesidad accesibles en el valle. Como sugiere Tristan Platt (1987) para el caso de los llameros de Lípez, los carangas no eran ajenos a la intervención mercantil, pero contemplaban ésta dependiendo de sus necesidades o dentro de un calendario de actividades que no se subordinaba a los ritmos y exigencias de la industria minera.

Dentro de la división del trabajo, suponemos que eran los hombres los encargados de fundir el mineral, que recogían las mujeres, en guairas o pequeños hornos de fundición, utilizando tecnología tradicionalmente indígena. ${ }^{19}$

19 En el conflicto entre los mineros de Tarapacá y el ensayador de la Caja, este último se defendía de las acusaciones de las pérdidas al
Aunque también cabe la posibilidad que lo llevaran hasta un trapiche o ingenio donde en concierto con el dueño beneficiaran el mineral con azogue. ${ }^{20} \mathrm{El}$ subdelegado les pagaba seis pesos y cuatro reales por cada marco de plata en "piña o pasta". En Tarapacá el precio fijado para los marcos de plata que rescataban de los palliris era de seis pesos (Villalobos 1967: 199).

Tanto el pallaqueo (exterior mina) como el juqueo (interior mina), realizados por hombres o mujeres, fueron las actividades más extendidas en Carangas, donde las empresas mineras habían dejado de ser rentables y por tanto se mantenían muy pocas minas en labor. La mayoría de las vetas estaban agotadas y las minas inundadas, de manera que requerían para ponerlas al corriente un gran desembolso de capital. Esto había provocado el abandono del centro por parte de muchos mineros y azogueros de Carangas y el traslado hasta las minas de Huantajaya en Tarapacá. Hasta cierto punto, este abandono benefició a los indígenas y mestizos originarios y vecinos del partido que se encargaron de rentabilizar los desmontes y minas abandonadas consiguiendo más beneficios que

fundir las barras diciendo que las piñas de plata procedentes de Tarapacá traían muchas impurezas a diferencia de las que procedían de Carangas que "era plata de fundición" (AGI, Charcas, 490, años 1766-67, fs. 110-130).

${ }^{20}$ En Tarapacá, Roque Dorado y Diego García Iglesias beneficiaban el mineral que rescataban de buscones, jucos o mineros y también compraban marcos de plata. Ninguno de los dos tenía minas en 1767, pero años después en 1779 Roque Dorado registraba una mina en el mineral del Carmen (AGI, Charcas, 490, años 176667, fs. 110-130). 
a través del salario minero. ${ }^{21}$ El control de la actividad minera en pequeñas proporciones se aprecia en que no se registraban grandes cantidades de plata por parte de ningún minero azoguero de Carangas. Al final podemos afirmar que triunfó la minería informal si nos atenemos a la procedencia de los registros de plata de 1790 en la Caja Real de Carangas, donde se debía registrar la plata que provenía de este partido, aunque sabemos que también se registraba plata de Huantajaya (Tarapacá). Del total de la plata registrada en 1790, es decir: 22.657 marcos, el 80\% de ésta procedía de Tarapacá y el 20\% restante de Carangas y era registrada por indios y mestizos del partido. Los hermanos Cáceres eran indios ladinos naturales y residentes en Carangas. En el caso de Canaviri, aunque no lo podemos asegurar, pensamos que era igualmente indio o mestizo, y Ambrosio Cerezo Alderete, era un reconocido rescatista mestizo en este asiento minero. La plata que procedía de un azoguero asentado en Carangas era de Manuel Zorrilla y consistía en 346 pesos (Tabla 1).

\section{$*$ Conclusión}

La plata atrajo hasta Carangas a mucha gente interesa$\mathrm{da}$ en explotar las riquezas minerales a pesar de sus difíciles condiciones de habitabilidad para los españoles y foráneos que consideraban el territorio "hostil", "incómodo", "escaso de todo", "triste y melancólico" y además retirado de los grandes centros administrativos. La plata también había modificado su paisaje y había transformado la vida de sus habitantes. A las cargas impuestas por el sistema colonial, los carangas (aymaras y urus) tuvieron que soportar las presiones que los mineros y azogueros imponían para la explotación minera. Las coacciones institucionales o particulares provocaron diferentes respuestas en la población indígena, que fueron desde la resistencia pacífica hasta la rebelión en casos especiales como el protagonizado por la comunidad de Llanquera en 1732 o la participación en la sublevación de 1781 (Gavira 2008). El empleo en la actividad

\footnotetext{
${ }^{21}$ El asiento de minas de Salinas de Garcimendoza se encontraba prácticamente abandonado por los mineros españoles en el siglo XVIII, pero en la segunda mitad de este siglo encontramos en la Caja Real de Oruro que los indígenas estaban registrando minas en estos cerros (Gavira 2005).
}

minera no siempre fue prioritario en la economía familiar que tenía en la ganadería y el tradicional intercambio de productos con los valles una actividad preferente para conseguir productos no accesibles en su ecosistema serrano (Riviere 1982; Medinaceli 2010). El trabajo de las mujeres recogiendo mineral en los desmontes y el de los buscones y jucos suponía una alternativa a emplearse en las minas e ingenios para adquirir dinero o productos. Estas actividades se fueron haciendo mayoritarias en el partido a medida que los azogueros fueron abandonando el centro para instalarse en el mineral de Huantajaya. Pero si de alguna manera esto benefició a la población que se encontró con menos presiones a la hora de ser reclutada para el trabajo en las minas e ingenios, la economía en general se contrajo. La restricción de la demanda requerida en la producción y el beneficio de la plata, disminuyó el comercio de productos locales en manos indígenas como el sebo, la sal o el charqui. Redujo la demanda de diferentes servicios como era la arriería y el empleo de las llamas en las bajas de metal hasta los ingenios.

Hay evidencias suficientes para afirmar que la minería en Carangas durante la segunda mitad del siglo XVIII daba muestras de su decadencia. Pero queda pendiente de confirmar si el asiento minero estaba tan arruinado como las fuentes refieren a principios del siglo XIX. El informe de los oficiales de Oruro de 1804 calificaba al mineral de Carangas como "cadáver", haciendo alusión a que sólo ejercían la actividad minera los jucos, buscones y palliris. Un informe republicano de 1842 , que podría considerarse como el testamento de este mineral, decía que no se explotaba metal alguno y que no había ni "una sola mina en trabajo" (ABNB, MH, Prefectura de Oruro, recibidas, vol. $87, \mathrm{n}^{\circ} 25$. s/f). Habría que preguntarse hasta qué punto este informe no consideraba como actividad minera la labor de los carangas que recogían mineral entre los desmontes y minas abandonadas y lo vendían a los rescatistas o comerciantes. Al no tener institución encargada de registrar el mineral en la provincia (que pasó a depender del departamento de Oruro), resulta más difícil seguir los circuitos de la plata. Pero sospechamos que el abandono de Carangas no fue tan contundente como estos informes sugieren, puede que los informantes no estuviesen valorando la "minería informal" que, en pequeñas proporciones, realizaban los carangas. 


\section{* Referencias citadas}

\section{Fuentes documentales}

I. Archivo y Biblioteca Nacional de Bolivia (ABNB)

Minas:

Vol. 96, n 18, año 1785. "Pleito de Manuel Zorrilla por el robo de una barras de plata".

Vol. 96, n²0, año 1785. "Pleito entre los dos azogueros de Carangas y el subdelegado Dionisio Marín".

Vol. 92, n 20, año 1785. "Certificación de los oficiales reales de la Caja Real de Carangas".

Expedientes Coloniales (EC):

Año 1788, n 13. "Informe del subdelegado Don Pedro del Cerro Somiano".

Ministerio de Hacienda (MH):

Prefectura de Oruro, recibidas, vol. 87, n 25. "Gobernador de Carangas al prefecto de Oruro. Andamarca, 13 de octubre de $1842 "$

II. Archivo General de Indias (AGI)

Audiencia de Lima:

Legajo 1351. "Informe de O'Brien, Tarapacá, 29 de agosto de 1765".

Audiencia de Charcas:

Legajo 637, año 1784. "Carta-cuenta de Carangas, Ramo de Deudas".

Legajo 490, años 1766-67. "Testimonios de autos obrados por los oficiales reales de Carangas".

III. Biblioteca Británica (BB):

Add. Ms. 20.999. Año 1603. "Relación de la villa Imperial de Potosí".

\section{Publicaciones}

ACEVEDO, E. O. 1992. Las intendencias altoperuanas en el virreinato del Río de la Plata. Academia Nacional de la Historia, Buenos Aires.

ASSADOURIAN, S. 1979. "La producción de la mercancía dinero en la formación del mercado interno colonial. El caso del espacio peruano, siglo XVI". En Ensayos sobre el desarrollo económico en México y América Latina. E. Florescano (Comp.), pp. 223-292. Fondo de Cultura Económica, México.

BAKEWELL, P. 1976. Minería y sociedad en el México colonial. Zacatecas (1546-1700). FCE, México.
BRADING, D. 1975. Mineros y comerciantes en el México borbónico (1763-1810). FCE, México.

CAPOCHE, L. 1959 [1585]. Relación General de la Villa Imperial de Potosí. Lewis Hanke (Ed.). Biblioteca de Autores Españoles, T. CXXII, Madrid.

GAVIRA, M. C. 200o. Reclutamiento y remuneración de la mano de obra minera en Oruro, 1750-1810. Anuario de Estudios Americanos $57(1): 223-250$.

2005a. Historia de una crisis: La minería en Oruro a fines del período colonial. Universidad Mayor de San Andrés/Instituto Francés de Estudios Andinos/ Cooperación ASDI-SAREC, La Paz.

2005b. Producción de plata en el mineral de San Agustín de Huanjaya, 1750-1804. Chungara, Revista de Antropología chilena $37(1): 37-57$.

2008. Población indígena, sublevación y minería en Carangas, Universidad de Tarapacá e Instituto Francés de Estudios Andinos, Arica.

2013a. Minería en Chayanta. La sublevación indígena y el auge minero, 1775-1792. Plural Editores/UMSNH, La Paz.

2013b. Instrucciones para los subdelegados de la intendencia de Potosí realizadas por el Intendente Juan del Pino Manrique en 1784. Diálogo Andino. Revista de Historia, Geografía y Cultura Andina 42: 5-16.

GOLTE J. 1980. Repartos y Rebeliones, Instituto de Estudios Peruanos, Lima.

HIDALGO, J. 1987. Tierras, exacciones fiscales y mercado en las sociedades andinas de Arica, Tarapacá y Atacama, 1750-1790. En La Participación Indígena en los Mercados Surandinos. O. Harris, B. Larson y E. Tandeter (Comps.), pp. 193-231. CERES, La Paz.

LANGUE, F. y C. SALAZAR-SOLER. 1993. Dictionnaire des termes miniers en usage en Amérique espagnole (XVIe-XIXe siècle. Editions Recherche sur les Civilisations, París.

LARSON, B. 1983. Producción doméstica y trabajo femenino indígena en la formación de una economía mercantil colonial. Historia Boliviana 3 (2): 173-188.

MEDINACELLI, X. (Coord.), 2012. Turco Marka. Hombres, Dioses y Paisaje en la Historia de un pueblo orureño. IEB, Universidad Mayor de San Andrés y Centro Cultural Banco Central de Bolivia, La Paz. 
2010. Sariri. Los llameros y la construcción de la sociedad colonial. Asdi/Ifea/Plural/IEB, La Paz.

MENZ, von B. 1988. Coyuntura minera y protesta campesina en el centro de Nueva España, siglo XVIII. En La minería mexicana. De la colonia al siglo XX. I. Herrera (Comp.), pp. 23-46. Instituto Mora/El Colegio de Michoacán, México.

PLATT, T. 1987. Calendarios tributarios e intervención mercantil. La articulación estacional de los ayllus de Lípez con el mercado minero potosino (siglo XIX). En La Participación Indígena en los Mercados Surandinos. Estrategias y reproducción social. Siglo XVI a XX. O. Harris, B. Larson y E. Tandeter (Comps.), pp. 471-557. CERES, La Paz.

1996. Producción, Tecnología y Trabajo en la Rivera de Potosí durante la República Temprana. AHILA, Cuadernos de Historia Latinoamericana 3, Münster-Hamburg.

RIVIERE, G. 1982. Sabaya: Estructures socio-économiques et représentations symboliquesdans le Carangas, Bolivie. Tesis de doctorado, École des Hautes Études en Sciences Sociales, París.

SAGUIER, E. 1992. La corrupción de la burocracia colonial Borbónica y los orígenes del federalismo: El caso del virreinato del Río de la Plata. Jahrbuch für Geschichte von Staat, Wirtschaft und Gesellschaft Lateinamerikas 29, Colonia.

SALA I VILA, N. 1996. Y se armó el Tole Tole, Tributo indígena y Movimientos sociales en el Virreinato del Perú, 1784-1814, Instituto de Estudios Regionales José María Arguedas, Lima.

STERN, S. 1990. Nuevas aproximaciones al estudio de la conciencia y las rebeliones campesinas: las implicaciones de la experiencia andina. En Resistencia, Rebelión y Conciencia en los Andes. S. Stern (Comp.), pp. 24-41. Instituto de Estudios Peruanos, Lima.

VILLALOBOS, S. 1967. La economía de un desierto. Pontificia Universidad Católica de Chile, Santiago. 